\title{
The genetic structure of the gynodioecious Kallstroemia grandiflora (Zygophyllaceae): the role of male sterility and colonization history
}

\author{
E Cuevas ${ }^{1}, \mathrm{DM}$ Arias $^{2}, \mathrm{CA}$ Domínguez $^{3}, \mathrm{RA}$ Castillo $^{4}$ and F Molina-Freaner ${ }^{1}$ \\ ${ }^{1}$ Departamento de Ecología de la Biodiversidad, Instituto de Ecología UNAM, Apartado Postal 1354, Hermosillo, Sonora C.P. 83000, \\ México; ${ }^{2}$ Centro de Educación Ambiental e Investigación Sierra de Huautla, UAEM, Cuernavaca, Morelos C.P. 62210, México; \\ ${ }^{3}$ Departamento de Ecología Evolutiva, Instituto de Ecología UNAM, Apartado Postal 70-275, México D.F. C.P. 04510, México; \\ ${ }^{4}$ Departamento de Investigaciones Cientificas y Tecnologicas de la Universidad de Sonora, Apartado Postal 1819, Hermosillo, \\ Sonora C.P. 83000 , Mexico
}

\begin{abstract}
In gynodioecious populations, the frequency of females is expected to have a strong influence on the contemporary genetic structure of populations. Historical patterns of range contraction and expansion are also known to influence the genetic diversity of plant populations. We explore the influence of male sterility and colonization history on the genetic diversity in populations of Kallstroemia grandiflora along the Pacific of México. Both the overall population $F_{\text {is }}$ and $F_{\text {is }}$ values of hermaphrodites showed a negative
\end{abstract}

association with female frequency. Genetic diversity declined with latitude. Our results provide evidence that females have a significant effect on the genetic structure as predicted by theoretical models and provide support for the hypothesis that historical processes have modified the genetic structure of $K$. grandiflora.

Heredity (2006) 97, 269-274. doi:10.1038/sj.hdy.6800849; published online 31 May 2006

Keywords: genetic structure; gynodioecy; Kallstroemia; male sterility; Sonoran desert

\section{Introduction}

Current and historical processes are known to influence the contemporary genetic structure of plant populations. The major features of the breeding system are also critical determinants of the genetic structure of plants. With complete self-fertilization heterozygosity is expected to rapidly decline, whereas with random outcrossing heterozygosity is maintained in populations (Hedrick, 2000). Self-compatible gynodioecious species comprise both hermaphrodite plants that are capable of selfing and female plants that are obligate outcrossers. Gouyon and Couvet (1987) proposed that because of the different patterns of mating exhibited by female and hermaphrodite plants of gynodioecious species, the frequency of females should have a strong influence on the genetic structure of populations. If hermaphrodite plants are predominantly selfers, heterozygote deficiency for females, hermaphrodites and the whole population are expected to decline as female frequency increases. Consequently overall heterozygosity levels would be expected to increase with male sterility (Gouyon and

Correspondence: F Molina-Freaner, Departamento de Ecología de la Biodiversidad, Instituto de Ecología UNAM, Apartado Postal 1354, Hermosillo, Sonora C.P. 83000, Mexico.

E-mail: freaner@servidor.unam.mx

Received 2 August 2005; accepted 25 April 2006; published online 31 May 2006
Vernet, 1982). In addition, if there is maternal inheritance of sex (ie if female plants have relatively more female progeny than hermaphrodites), females are expected to be more heterozygous than hermaphrodites (Gouyon and Couvet, 1987). The few studies that have explored these predictions for self-compatible gynodioecious species have failed to find empirical support (Tarayre and Thompson, 1997; but see Medrano et al, 2005).

Historical patterns of gene flow are also known to influence the genetic structure and phylogeography of plant populations (Soltis et al, 1997; Nason et al, 2002). The geographic distribution of many plant species has been subject to range expansion and contraction in response to climatic changes (ie glaciations, Comes and Kadereit, 1998). If these cycles have been associated with bottlenecks in population size and recolonization from a refugial source, range expansion is expected to generate a genetic structure in which genetic diversity declines with increasing latitude (Hewitt, 1996; Nason et al, 2002).

Paleobotanical studies based on packrat middens have provided evidence about the history of the vegetation of North American deserts and migration of several plant species (Van Devender, 1990, 2002). The paleobotanical evidence indicates that the geographic range of many North American desert plants have been subject to expansion and contraction in response to climatic change (Van Devender, 1990, 2002). Few studies, have explored whether North American desert plants show evidence of declining genetic diversity with increasing latitude. Two 
columnar cacti from Baja California show such a trend, apparently as a consequence of repeated cycles of range expansion and contraction from Southern refuges (Nason et al, 2002; Clark-Tapia and Molina-Freaner, 2003). Very few studies, however, have explored this issue on mainland Mexico (Silva-Montellano and Eguiarte, 2003).

Kallstroemia grandiflora is an annual, self-compatible gynodioecious species with a range of variation in male sterility from 0 to $44 \%$ among populations (Cuevas E, personal observation). The anthers of pistillate flowers of K. grandiflora show an early degeneration of tapetal cells during pollen grain development. This fact, along with the lack of female reproductive compensation (Cuevas et al, 2005), suggests a maternal component of inheritance. It is thus a suitable system to explore the influence of male sterility on the genetic structure of its populations. In addition, it has a wide latitudinal distribution in North American arid regions, from the Sonoran and Chihuahuan deserts to the tropical dry forests in central México (Porter, 1969), offering an excellent opportunity to explore the relationship between genetic diversity and latitude. In this paper, we describe the geographic distribution of male sterility in populations of $K$. grandiflora from México and test whether female frequencies have any effect on the genetic structure. Finally, we explore whether genetic diversity declines with latitude through the distribution range of $K$. grandiflora along the Pacific coast of México.

\section{Materials and methods}

\section{Study species}

K. grandiflora belongs to the Zygophyllaceae, a small family composed of 25 genera and 250 species, distributed mostly in the arid tropics and subtropics (Porter, 1969; Sheahan and Chase, 1996). The distribution of $K$. grandiflora ranges from the Sonoran and Chihuahuan deserts of North America to the semiarid west coast of México along the limits of the states of Guerrero and Michoacán (Porter, 1969). Pistillate flowers from females have white reduced anthers and smaller corollas $(2.8 \pm 0.51 \mathrm{~cm}$; mean \pm 1 s.d. here and hereafter $)$ than the perfect flowers of hermaphrodites $(4.4 \mathrm{~cm} \pm 0.54$; Cuevas et al, 2005). Pollen release and stigma receptivity are simultaneous and hermaphrodite flowers are self-compatible (Porter, 1969; Cuevas et al, 2005). Throughout its range, flowers are visited by more than 40 species of insects, mainly bees and wasps (Cazier and Linsley, 1974, 1975; Osorio-Beristain et al, 1997). Based on the behavior of flower visitors, at least 10 species could be considered as effective pollinators (Cazier and Linsley, 1974, 1975).

\section{Sampling and estimation of male sterility}

During August 2002, we estimated the frequency of male sterility in 15 populations of $K$. grandiflora located along a latitudinal gradient. We tried to cover the entire range of

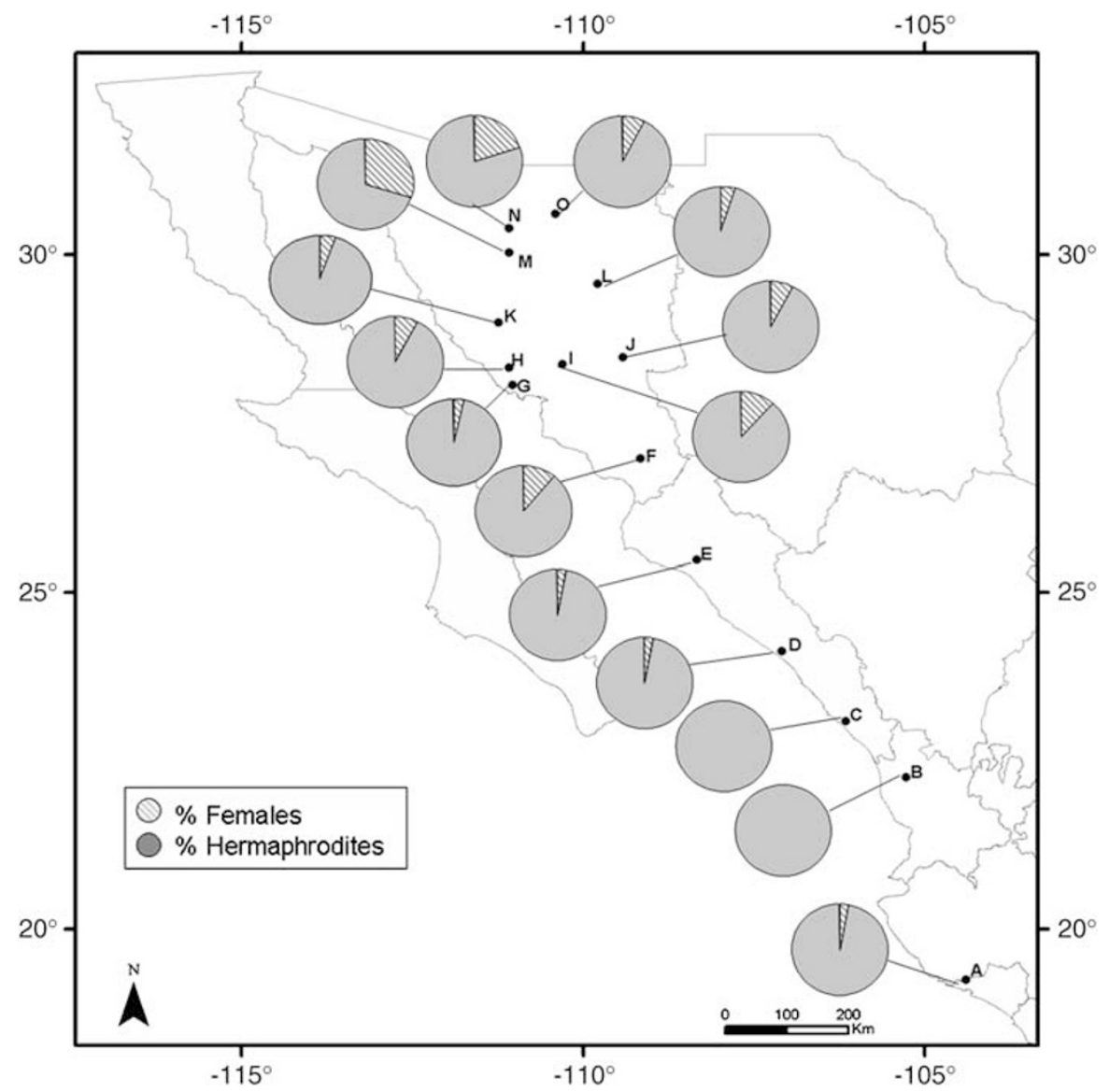

Figure 1 Map showing the location of the 15 sampled populations of $K$. grandiflora along the Pacific of México and the frequency of female and hermaphrodite plants in each population. Letters refers to the population name in Table 1. See Table 1 for precise population location. 
Table 1 Measures of genetic diversity in populations of K. grandiflora from western México

\begin{tabular}{|c|c|c|c|c|c|c|c|c|}
\hline Population & Latitude ${ }^{\circ} \mathrm{N}$ & Longitude ${ }^{\circ} \mathrm{W}$ & A & $\mathrm{H}_{o}$ & $\mathrm{H}_{e}$ & $\mathrm{~F}_{i s}$ & $\%$ Male sterility & $\begin{array}{c}\text { Sample size } \\
\text { (Hermaphrodites/females) }\end{array}$ \\
\hline A-Melaque & $19^{\circ} 13^{\prime} 47^{\prime \prime}$ & $104^{\circ} 42^{\prime} 33^{\prime \prime}$ & 2.0 & 0.223 & 0.275 & 0.189 & 3.0 & $38 / 2$ \\
\hline B-Acaponeta & $22^{\circ} 32^{\prime} 29^{\prime \prime}$ & $105^{\circ} 28^{\prime} 21^{\prime \prime}$ & 2.0 & 0.176 & 0.293 & 0.399 & 0 & $40 / 0$ \\
\hline C-Mazatlán & $23^{\circ} 09^{\prime} 47^{\prime \prime}$ & $106^{\circ} 05^{\prime} 40^{\prime \prime}$ & 2.0 & 0.197 & 0.273 & 0.278 & 0 & $40 / 0$ \\
\hline D-Culiacán & $24^{\circ} 20^{\prime} 39^{\prime \prime}$ & $107^{\circ} 05^{\prime} 55^{\prime \prime}$ & 1.9 & 0.211 & 0.272 & 0.224 & 3.0 & $38 / 2$ \\
\hline E-Mochis & $25^{\circ} 42^{\prime} 23^{\prime \prime}$ & $108^{\circ} 42^{\prime} 41^{\prime \prime}$ & 2.1 & 0.249 & 0.320 & 0.221 & 3.5 & $37 / 3$ \\
\hline F-Alamos & $27^{\circ} 05^{\prime} 51^{\prime \prime}$ & $109^{\circ} 11^{\prime} 26^{\prime \prime}$ & 2.1 & 0.222 & 0.291 & 0.237 & 11.0 & $35 / 5$ \\
\hline G-Guaymas & $28^{\circ} 12^{\prime} 08^{\prime \prime}$ & $111^{\circ} 00^{\prime} 47^{\prime \prime}$ & 2.0 & 0.159 & 0.303 & 0.475 & 4.0 & $38 / 2$ \\
\hline H-La Paloma & $28^{\circ} 29^{\prime} 40^{\prime \prime}$ & $111^{\circ} 02^{\prime} 64^{\prime \prime}$ & 1.9 & 0.203 & 0.254 & 0.2 & 8.0 & $36 / 4$ \\
\hline I-La Colorada & $28^{\circ} 45^{\prime} 68^{\prime \prime}$ & $110^{\circ} 28^{\prime} 64^{\prime \prime}$ & 1.9 & 0.184 & 0.225 & 0.182 & 12.0 & $35 / 5$ \\
\hline J-Las Guásimas & $28^{\circ} 53^{\prime} 71^{\prime \prime}$ & $109^{\circ} 53^{\prime} 03^{\prime \prime}$ & 1.9 & 0.194 & 0.253 & 0.233 & 8.0 & $36 / 4$ \\
\hline K-El Tonuco & $29^{\circ} 08^{\prime} 24^{\prime \prime}$ & $111^{\circ} 23^{\prime} 25^{\prime \prime}$ & 1.7 & 0.208 & 0.262 & 0.206 & 5.0 & $37 / 3$ \\
\hline L-Ures & $29^{\circ} 30^{\prime} 00^{\prime \prime}$ & $110^{\circ} 50^{\prime} 00^{\prime \prime}$ & 1.8 & 0.169 & 0.261 & 0.352 & 5.0 & $37 / 3$ \\
\hline M-Benjamin Hill & $30^{\circ} 13^{\prime} 58^{\prime \prime}$ & $111^{\circ} 05^{\prime} 47^{\prime \prime}$ & 1.8 & 0.23 & 0.263 & 0.125 & 30.0 & $28 / 12$ \\
\hline N-Santa Ana & $30^{\circ} 35^{\prime} 50^{\prime \prime}$ & $111^{\circ} 02^{\prime} 16^{\prime \prime}$ & 1.9 & 0.201 & 0.248 & 0.189 & 20.0 & $32 / 8$ \\
\hline O-Cananea & $30^{\circ} 59^{\prime} 37^{\prime \prime}$ & $110^{\circ} 33^{\prime} 38^{\prime \prime}$ & 1.8 & 0.195 & 0.223 & 0.125 & 8.0 & $36 / 4$ \\
\hline Mean & & & 1.92 & 0.201 & 0.267 & 0.242 & 8.0 & \\
\hline SD & & & 0.11 & 0.023 & 0.026 & 0.097 & 7.95 & \\
\hline
\end{tabular}

$A$, mean number of alleles per locus; $H_{\mathrm{o}}$ observed heterozygosity; $H_{\mathrm{e}}$, expected heterozygosity; reported values are for both polymorphic (10) and monomorphic (4) loci. $F_{\text {is, }}$ measures deviation from Hardy-Weinberg proportions (values for polymorphic loci); \% Male sterility, percentage of male sterility; Sample size (Hermaphrodites/Females): number of hermaphrodite and female plants sampled per population. $\mathrm{SD}$ is the standard deviation.

distribution of this species in México and the range of variation in male sterility (Figure 1, Table 1). In each population, we used line transects to sample at least 200 plants, and the sex-morph of each plant was recorded using three or more open flowers. In each of the 15 populations, mature leaf samples from 40 individuals separated at least 5-10 m from each other were collected for genetic analyses. Female and hermaphrodite plants were sampled in proportion to their frequency in each population. Samples were immediately stored in liquid nitrogen and once in the lab they were kept in an ultracold freezer at $-70^{\circ} \mathrm{C}$.

\section{Electrophoretic procedures}

Each sample was ground in a cold mortar with two to three drops of the Tris-HCL extraction buffer (Wendel and Weeden, 1989). Extracts were absorbed in $1.5 \times 10 \mathrm{~mm}$ paper wicks. Allozymes were run in $11.5 \%$ starch and $5 \%$ sucrose gels. Three buffer systems were used to assay eight enzyme systems and 14 loci. Enzyme systems were selected on the basis of resolution and reproducibility. Buffer 8 from Soltis et al (1983) was used to assay malic enzyme (ME), phosphoglucoisomerase (PGI), leucine aminopeptidase (LAP), oxaloacetate transaminase (GOT) and anodic peroxidase (APX). Buffer 9 from Soltis et al (1983) was used to assay phosphoglucomutase (PGM) and shikimate dehydrogenase (SDH). Buffer D of Wendel and Stuber (1984) was used to assay malate dehydrogenase (MDH).

Loci and alleles were designated by relative protein mobility, with lower numbers assigned to those farther from the origin. Staining procedures correspond to those of Wendel and Weeden (1989) for LAP, MDH, ME, PGM, APX, PGI, SDH and Murphy et al (1990) for GOT.

\section{Data analysis}

Genetic diversity measures were obtained using POPGENE (Yeh and Yang, 1999). These measures include the percentage of polymorphic loci $(P)$, mean number of alleles per locus $(A)$, observed $\left(H_{\mathrm{o}}\right)$ and expected heterozygosity $\left(H_{\mathrm{e}}\right)$. Wright's $F$ statistics $\left(F_{\text {is }} F_{\text {st }}\right.$ and $\left.F_{\text {it }}\right)$ were obtained and their $95 \%$ confidence intervals $(\mathrm{CI})$ were estimated following the methods of Weir and Cockerham (1984). CI were obtained by bootstrapping over loci (Yeh and Yang, 1999). Randomization methods were used to test whether $F$ values showed significant deviations from zero using FSTAT (Goudet, 1995). Nei's (1972) genetic distances were estimated between all pairs of populations and used to generate a neighbor-joining phenogram using PHYLIP, version 3.6 (Felsenstein, 2004). A total of 1000 bootstraps over loci were used to estimate the support for branch points. Regression analyses were used to explore the influence of female frequency (arcsine transformed), on heterozygote deficiency $\left(F_{\text {is }}\right)$, and the expected and observed heterozygosity $\left(H_{\mathrm{e}}\right.$ and $\left.H_{\mathrm{o}}\right)$ for females, hermaphrodites and overall population values. We used regression analyses to explore the relationship between $A, H_{o}, H_{e}$ and latitude. Finally, hermaphrodite and female mean values of $F_{\text {is }}$ were compared through a one-way ANOVA. All statistical analyses were carried out using JMP version 3.2 (SAS Institute, 1997)

\section{Results}

Geographic variation of male sterility

Male sterility ranged from zero in Acaponeta and Mazatlán to $30 \%$ in Benjamin Hill, along the Pacific of México (Figure 1, Table 1). We found a significant positive association between the frequency of females and latitude along the distribution range in México $\left(P<0.01, R^{2}=0.5\right.$, Figure 2$)$.

\section{Genetic diversity and structure}

In all, 10 out of 14 loci were polymorphic $(71.4 \%)$. MDH, ME, LAP-1 and GOT-1 were monomorphic in all populations. The average number of alleles per locus (A) was 1.92 while the overall genetic diversity $\left(H_{\mathrm{e}}\right)$ was 


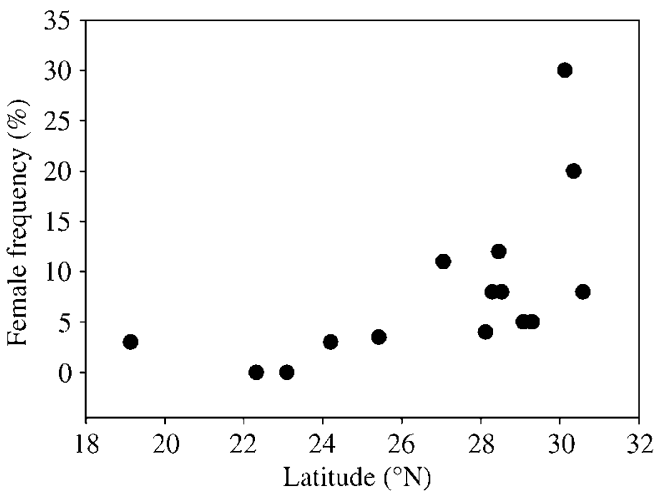

Figure 2 Male sterility in 15 populations of $K$. grandiflora as a function of latitude along the Pacific coast of México.

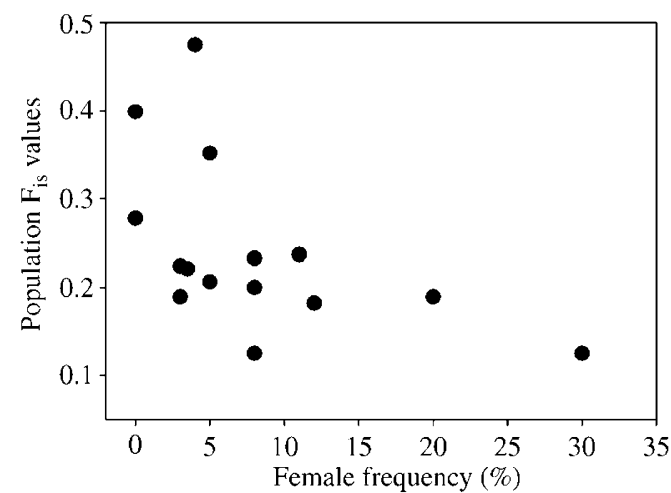

Figure 3 Heterozygote deficiency $\left(F_{\text {is }}\right)$ for populations of $K$. grandiflora as a function of female frequency along the Pacific coast of Mexico. Mean $F_{\text {is }}$ values calculated just for polymorphic loci.

0.26 , and the average observed heterozygosity $\left(H_{\mathrm{o}}\right)$ was 0.20 (Table 1). Given the difference between $H_{\mathrm{e}}$ and $H_{\mathrm{o}}$, $F_{\text {is }}$ was positive for all populations (Table 1 ) indicating a deficiency of heterozygotes. Mean estimates of Wright's $F$ statistics were 0.24 (95\% CI: $0.09-0.37)$ for $F_{\mathrm{is}}, 0.23$ (95\% CI: $0.16-0.29)$ for $F_{\text {st }}$ and 0.42 (95\% CI: 0.28-0.52) for $F_{\text {it }}$ and the randomization tests indicated that all the parameters were significantly different from zero $(P<0.001)$

\section{Influence of male sterility}

Linear regression analyses showed that female frequency had a significant effect upon the genetic structure of K. grandiflora. As predicted, the frequency of females showed a negative association with both the overall population $(P<0.05$, Figure 3$)$ and hermaphrodite $F_{\text {is }}$ values $(P<0.01)$, but not with female $F_{\text {is }}$ values $(P=0.47)$. Female frequency was not correlated with expected or observed population heterozygosity neither with heterozygosity in hermaphrodites or females. As expected, mean $F_{\text {is }}$ for hermaphrodites was significantly greater than for females $(0.223$ and -0.09 respectively; $P<0.01)$.

\section{Association with latitude}

Linear regression analyses indicated genetic diversity declines with latitude (Figure 4 ) as quantified by both $H_{e}$ $(P<0.05)$ and $A(P<0.05)$. The proportion of polymorphic loci remained constant throughout the latitu-
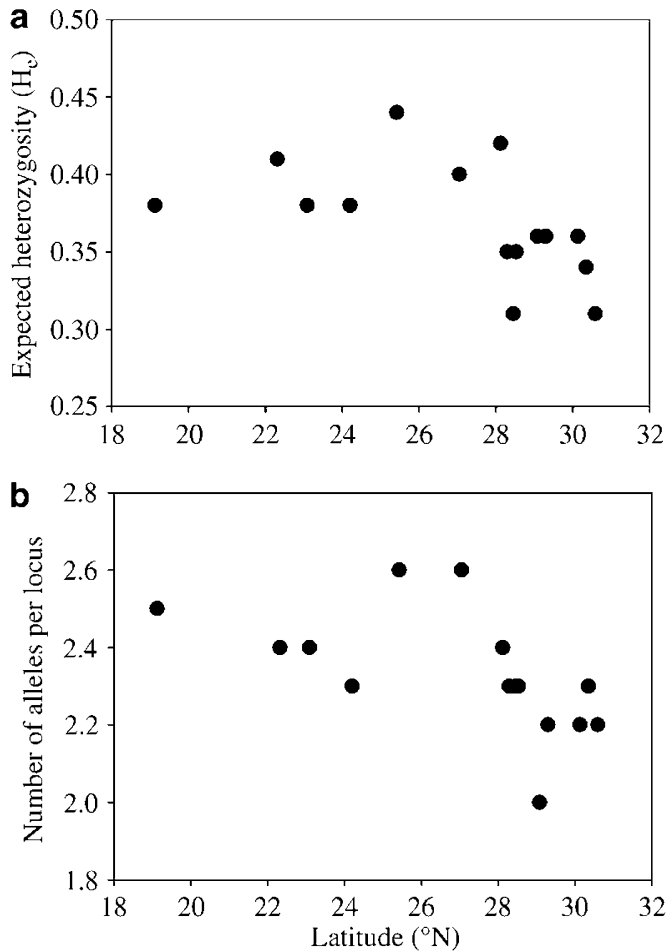

Figure 4 Genetic diversity as a function of latitude in populations of K. grandiflora: (a) expected heterozygosity as a function of latitude and (b) average number of alleles per locus as a function of latitude. Mean values for polymorphic loci.

dinal range $(71.4 \%)$. The population neighbor-joining phenogram showed some geographic pattern: Southern populations (B, C, A) usually occupied the base while Northern populations $(\mathrm{O}, \mathrm{N}, \mathrm{L})$ occupied terminal branches (Figure 5).

\section{Discussion}

We have shown that both male sterility and latitude influence the genetic structure of K. grandiflora. As far as we know, this is the first well-supported case of female frequency influencing heterozygote deficiency across the range of a gynodioecious species. Moreover, our data also show that genetic diversity declines with latitude as expected under cycles of range contraction and recolonization from a single refugial source.

\section{Influence of male sterility on the genetic structure}

Under nucleo-cytoplasmic inheritance, females are expected to influence the genetic structure of gynodioecious species by two mechanisms. If hermaphrodites are predominantly selfers and female are obligate outcrossers, hermaphrodite plants are expected to show greater levels of heterozygote deficiency than females. In addition, heterozygote deficiency in hermaphrodites is expected to decline as females increase in frequency (Gouyon and Vernet, 1982; Gouyon and Couvet, 1987). Our data on K. grandiflora support both predictions as significant differences in $F_{\text {is }}$ were detected between sexes and female frequency had a significant effect on $F_{\text {is }}$ of hermaphrodites and population $F_{\text {is }}$ values.

Female frequency is also expected to influence the overall heterozygosity of gynodioecious plants (Gouyon 


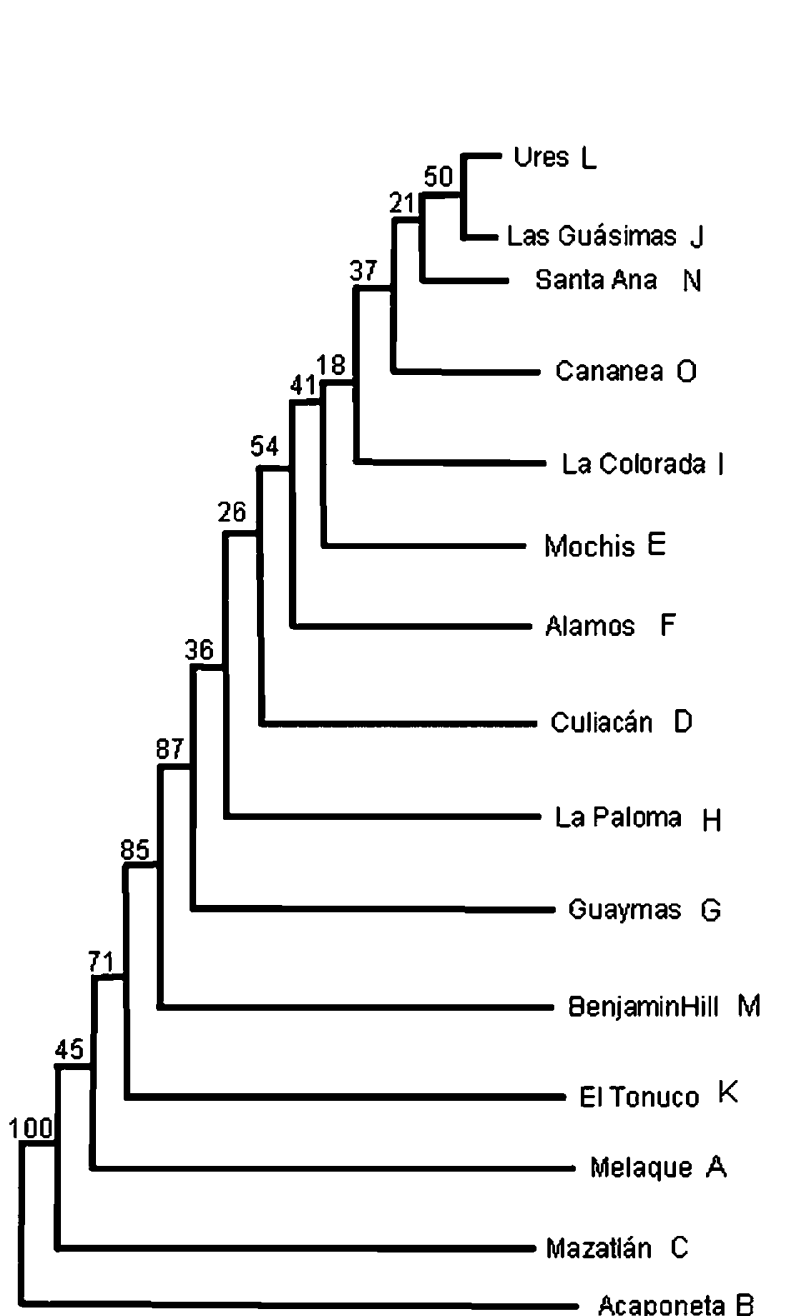

Figure 5 Neighbor-joining phenogram based on Nei's (1972) genetic distances (D) among the 15 populations of $K$. grandiflora. Numbers represent the percentage of bootstrap values $(1000$ replicates) supporting the branch.

and Couvet, 1987). However, our data provided no support for this prediction as female frequency did not have a significant effect on $\mathrm{H}_{\mathrm{e}}$ and $H_{\mathrm{o}}$. There are, however, several factors that may modify the predicted relationships. First, the historical pattern of range contraction and expansion may have generated a latitudinal decline in $H_{\mathrm{e}}$ and given that male sterility is concentrated in Northern Mexico, high levels of female frequency occur in areas of reduced $H_{\mathrm{e}}$. Thus, the expected relationship between female frequency and $H_{\mathrm{e}}$ may have been modified by the genetic signature left by historical patterns of recolonization. Second, the model of Gouyon and Vernet (1982) assumes that hermaphrodites are predominantly selfers, whereas variation in outcrossing rates may modify the predicted relationship between male sterility and $H_{\mathrm{o}}$. Thus, colonization history and variation in outcrossing rates might have modified the expected relationship between female frequency and heterozygosity in K. grandiflora.

\section{Association of male sterility with latitude and colonization history}

One of the most striking results from this study is the correlation between male sterility and genetic diversity with latitude. It is well known that besides genetic factors implicated in sex determination in gynodioecious species, ecological factors (ie pollinator availability, water availability or soil quality) are often involved in sex-ratio variation (McCauley and Brock, 1998; Delph and Carroll, 2001; Vaughton and Ramsey, 2004). Given that populations with greater frequencies of females were found in the Sonoran desert, it is possible that the pattern observed in K. grandiflora reflects an association with environmental stress as found in other species (ie Vaughton and Ramsey, 2004). Thus, future studies should evaluate whether water availability or rainfall predictability play important roles in the dynamics of male sterility in K. grandiflora.

The observed pattern of declining genetic diversity with latitude is consistent with the hypothesis of recurrent cycles of range contraction and recolonization associated with frequent bottlenecks (Hewitt, 1996; Nason et al, 2002). The position of Southern and Northern populations in the population phenogram provides partial support for this hypothesis. However, future studies employing further molecular markers are needed in order to explore in detail the history of colonization and the phylogeographic structure of K. grandiflora. In addition, nonequilibrium models should be explored as it is possible that populations in the Sonoran Desert are subject to recurrent local extinction due to the dynamics imposed by unpredictable rainfall events that are likely to affect neutral markers (Pannell and Charlesworth, 1999).

Comparison with other species

The level of genetic diversity observed in K. grandiflora is greater than mean values detected in annual plants $\left(H_{\mathrm{e}}=0.15\right.$; Hamrick and Godt, 1996), but fall within the range observed for other members of the Zygophyllaceae $\left(H_{\mathrm{e}}=0.20\right.$ and 0.28 for Larrea tridentata and Larrea divaricata, respectively, Cortes and Hunziker, 1997). Genetic differentiation in K. grandiflora is lower than mean values for annual plants $\left(F_{\mathrm{st}}=0.36\right.$; Hamrick and Godt, 1996). However, $F_{\text {is }}$ values in populations of $K$. grandiflora fall within the range observed in populations of the gynodioecious Silene vulgaris $\left(F_{\text {is }}=0.22\right.$; McCauley, 1998) but lower than the reported value for one population of the gynodioecious Chionographis japonica $\left(F_{\text {is }}=0.65\right.$, Maki, 1992). The observed $F_{\text {is }}$ values in $K$. grandiflora could be partially generated by some degree of self-fertilization in hermaphrodites and/or biparental inbreeding in females given the short inter-plant distances and the low capacity for seed dispersal (Porter, 1969). Thus, future studies should explore the temporal and geographic variation in multilocus outcrossing rate in hermaphrodite and female plants in order to evaluate their role generating deviations from Hardy-Weinberg.

\section{Acknowledgements}

We thank Luis Eguiarte and Raúl Alcalá for critical comments on previous versions of the manuscript, Gumersindo Sánchez and José Martínez for Lab and Field assistance and CONACYT (34889-V) for financial support and a scholarship to EC. 


\section{References}

Cazier MA, Linsley EG (1974). Foraging behavior of some bees and wasps at Kallstroemia grandiflora flowers in Southern Arizona and New Mexico. Am Museum Novitates 2546: 1-20.

Cazier MA, Linsley EG (1975). Bee and wasp visitors to Kallstroemia grandiflora after two years of drought. Pan-Pacific Entomol 51: 248-253.

Clark-Tapia R, Molina-Freaner F (2003). The genetic structure of a columnar cactus with a disjunct distribution: Stenocereus gummosus in the Sonoran desert. Heredity 90: 443-450.

Comes HP, Kadereit JW (1998). The effect of quaternary climatic change on plant distribution and evolution. Trends Plant Sci 3 : 432-438.

Cortes MC, Hunziker J (1997). Isozymes in Larrea divaricata and Larrea tridentata (Zygophyllaceae): A study of two amphitropical vicariants and autopolyploids. Genetica 101: 115-124.

Cuevas E, Márquez-Guzmán J, Domínguez CA, Molina-Freaner F (2005). Evidence of gynodioecy in Kallstroemia grandiflora (Zygophyllaceae): microsporogenesis in hermaphrodite and female plants and lack of reproductive compensation. Int $J$ Plant Sci 166: 481-491.

Delph L, Carroll S (2001). Factors affecting relative seed fitness and female frequency in a gynodioecious species, Silene vulgaris. Evol Ecol Res 3: 487-504.

Felsenstein J (2004). PHYLIP (Phylogenetic Inference Package) version 3.6. Departmen of Genetics, University of Washington: Seattle, WA, USA.

Goudet J (1995). Fstat version 1.2: a computer program to calculate F statistics. J Hered 86: 485-486.

Gouyon H, Vernet P (1982). The consequences of gynodioecy in natural populations of Thymus vulgaris L. Theor Appl Genet 61: 315-320.

Gouyon PH, Couvet D (1987). A conflict between two sexes, females and hermaphrodites. In: Stearns SC (ed) The Evolution of Sex and its Consequences. Birkhauser Verlag Basel: Boston. pp 245-261.

Hamrick JL, Godt MJ (1996). Effects of life history traits on genetic diversity in plants. Philos Trans $R$ Soc Lond Ser B Biol Sci 351: 1291-1298.

Hedrick WP (2000). Genetics of Populations. Jones and Bartlett publishers: Sudbury, Massachusetts.

Hewitt GM (1996). Some genetic consequences of ice ages, and their role in divergence and speciation. Biol J Linn Soc 58: 247-276.

Maki M (1992). Fixation indices and genetic diversity in hermaphroditic and gynodioecious populations of japanese Chionographis (Liliaceae). Heredity 68: 329-336.

McCauley D (1998). The genetic structure of a gynodioecious plant: nuclear and cytoplasmic genes. Evolution 52: 255-260.

McCauley D, Brock M (1998). Frequency-dependent fitness in Silene vulgaris, a gynodioecious plant. Evolution 52: 30-36.

Medrano M, Alonso C, Herrera CM (2005). Mating system, sex ratio and the persistence of females in the gynodioecious shrub Daphne laureola L. (Thymelaceae). Heredity 94: 37-43.

Murphy RW, Sites JW, Buth D, Haufler CH (1990). Proteins: isozyme electrophoresis. In: Hills D, Moritz C, Mable B (eds) Molecular Systematics. Sinauer Associates: Sundeland. pp 53-120.
Nason JD, Hamrick JL, Fleming TH (2002). Historical vicariance and postglacial colonization effects on the evolution of genetic structure in Lophocereus, a Sonoran deser columnar cactus. Evolution 56: 2214-2226.

Nei M (1972). Genetic distance between populations. Am Nat 106: 283-292.

Osorio-Beristain M, Domínguez CA, Eguiarte LE, Benrey B (1997). Pollination efficiency of native and invading africanized bees in the tropical dry forest annual plant, Kallstroemia grandiflora Torr ex Gray. Apidologie 28: 11-16.

Pannell JR, Charlesworth B (1999). Neutral genetic diversity in a metapopulation with recurrent local extinction and recolonization. Evolution 53: 664-676.

Porter D (1969). The genus Kallstroemia (Zygophyllaceae). Contrib Gray Herbarium, Harvard Univ 198: 41-153.

SAS Institute (1997). JMP Statistical Software Package, version 3.2 edn. SAS Insitute inc: Cary, NC.

Sheahan MC, Chase MW (1996). A phylogenetic analysis of Zygophyllaceae R.Br. based on morphological, anatomical and rbcL sequence data. Bot J Linn Soc 122: 279-300.

Silva-Montellano A, Eguiarte EL (2003). Geographic patterns in the reproductive ecology of Agave lechuguilla (Agavaceae) in the Chihuhuan desert. II. Genetic variation, differentiation and inbreeding estimates. Am J Bot 90: 700-706.

Soltis DE, Haufler CH, Darrow D, Gastony G (1983). Starch gel electrophoresis of Ferns: A compilation of grinding buffers, gel and electrode buffers, and staining schedules. Am Fern J 73: 9-27.

Soltis DE, Gitzendanner MA, Strenge DD, Soltis PS (1997). Chloroplast DNA intraspecific phylogeography of plants from the Pacific Northwest of North America. Plant Syst Evol 206: 353-373.

Tarayre M, Thompson JD (1997). Population genetic structure of the gynodioecious Thymus vulgaris L. (Labiatae) in Southern France. J Evol Biol 10: 157-174.

Van Devender TR (1990). Late quaternary vegetation and climate of Sonoran Desert, United states and Mexico. In: Betancourt JL, Van Devender TR, Martin PS (eds) Packrat Middens: The Last 40000 Years of Biotic Change. University of Arizona Press: Tucson, AZ. pp 134-164.

Van Devender TR (2002). Enviromental history of the Sonoran desert. In: Fleming TH, Valiente-Banuet A (eds) Evolution, Ecology and Conservation of Columnar Cacti and Their Mutualists. University of Arizona Press: Tucson, AZ. pp 3-24.

Vaughton G, Ramsey M (2004). Dry environments promote the establishment of females in monomorphic populations of Wurmbea biglandulosa (Colchicaceae). Evol Ecol 18: 323-341.

Wendel JF, Weeden NF (1989). Visualization and Interpretation of Plant Isozymes. In: Soltis DE, Soltis PS (eds) Isozymes in Plant Biology. Dioscorides Press: Portland, OR. pp 5-45.

Weir BS, Cockerham CC (1984). Estimating F-statistic for the analysis of population structure. Evolution 38: 1358-1370.

Wendel JF, Stuber CW (1984). Plant isozymes: Enzymes studied and buffer systems for their electrophoretic resolution in starch gels. Isozyme Bull 17: 4-11.

Yeh F, Yang R (1999). POPGENE. Microsoft Window-based Freeware for Population Genetic Analysis. Version 1.31, University of Alberta: Edmonton, Alberta, Canada. 